Research article

Open Access

\title{
Effect of the Two New Calcium Channel Blockers Mebudipine and Dibudipine in Comparison to Nifedipine on Vascular Flow of Isolated Rat Kidney
}

\author{
Lili SEPEHR-ARA ${ }^{1}$, Vahab BABAPOOR ${ }^{2}$, \\ Shahrbanoo ORYAN ${ }^{3}$, Massoud MAHMOUDIAN * 4
}

${ }^{1}$ Department of Biology, Science and Research Branch, Islamic Azad University, Tehran, Iran

2 Department of Physiology, Faculty of Veterinary Medicine, Tehran University, Tehran, Iran

${ }^{3}$ Department of Biology, Science Faculty, Teacher Training University, Tehran, Iran

${ }^{4}$ Razi Institute for Drug Research, Iran University of Medical Sciences, Tehran, Iran

* Corresponding author. E-mail: masmah99@iums.ac.ir (M. Mahmoudian)

Sci Pharm. 2009; 77: 805-815

doi:10.3797/scipharm.0906-12

Published: $\quad$ August $27^{\text {th }} 2009$

Accepted: $\quad$ August $26^{\text {th }} 2009$

Received: June $24^{\text {th }} 2009$

This article is available from: http://dx.doi.org/10.3797/scipharm.0906-12

(C) Sepehr-Ara et al.; licensee Österreichische Apotheker-Verlagsgesellschaft m. b. H., Vienna, Austria.

This is an Open Access article distributed under the terms of the Creative Commons Attribution License (http://creativecommons.org/licenses/by/3.0/), which permits unrestricted use, distribution, and reproduction in any medium, provided the original work is properly cited.

\begin{abstract}
In previous researches mebudipine and dibudipine two newly synthesized calcium channel blockers (CCBs) showed considerable relaxant effects on vascular and atrial smooth muscle cells. In this study we investigated the effects of these new drugs on vascular flow of isolated rat kidney and compare their potencies to nifedipine. It is concluded that mebudipine and dibudipine $(5 \mu \mathrm{M}$, $10 \mu \mathrm{M})$ caused concentration-dependent inhibition of increases in perfusion pressure induced by phenylephrine. Mebudipine $(10 \mu \mathrm{M})$ inhibited more greatly increases in perfusion pressure induced by phenylephrine compared to $(10 \mu \mathrm{M})$ nifedipine.
\end{abstract}

\section{Keywords}

Mebudipine - Dibudipine • Isolated rat kidney

\section{Introduction}

Strong evidence supports the idea that total peripheral resistance is increased in all from human and experimental hypertension [1]. Calcium channel blockers (CCBs) have ability to decrease peripheral vascular resistance [2]. Therefore are clinically useful vasodilators, 
used widely in treatment of hypertension [3]. These drugs also have ability to protect against renal injury [4]. It has been reported that CCBs preserve or even increase renal blood flow in the face of reduction in systolic blood pressure [5].

Different classes of CCBs have been introduced [6]. Among these classes dihydropyridine (DHP) derivatives are widely used because of their vasodilating activity and weak cardiodepressant action [7]. The adverse effect of these drugs (e. g. negative inotropism, heart blockade, reflex sympathetic activation) are agent dependent, not class-related [8]. Thus extensive researches have been carried out to synthesize new DHPs with improved properties. Mebudipine [tert-butyl methyl 2,6-dimethyl-4-(3-nitrophenyl)-1,4-dihydropyridine-3,5-dicarboxylate] and dibudipine [di-tert-butyl 2,6-dimethyl-4-(3-nitrophenyl)1,4-dihydropyridine-3,5-dicarboxylate], are two new 1,4-DHP calcium channel blockers synthesized by Mahmoudian et al. [7] with in-vitro half-lives of $22 \pm 7.1 \mathrm{~min}$ and $40 \pm 9.8 \mathrm{~min}$ respectively that were found to be significantly longer than that of nifedipine $5.5 \pm 1.1 \mathrm{~min}$ [9].

In a previous study mebudipine and dibudipine showed vasorelaxant effect on isolated rat aorta and human internal mammary artery [10]. These compounds reduced contraction force of rat left atrium and showed blood pressure lowering effect [11]. Mebudipine and dibudipine also showed a high potency in inhibiting the calcium evoked spikes in Helix aspersa [12]. Newer 1,4-DHPs address the problem of short half-life of nifedipine and may therefore be suitable for further development as potential therapeutic alternative to the existing 1,4-DHPs calcium channel blockers [9].

In this study we investigated the effect of mebudipine and dibudipine on renal blood flow in the isolated perfused rat kidney and compared their potencies to nifedipine.

The isolated perfused rat kidney has been recognized as a suitable preparation for studying many physiological and biochemical aspects of renal function such as hemodynamics, glumerular filtration rate (GFR) and overall handling of fluids [13]. Using this model it is possible to evaluate accurately the modulation by CCBs of renal vasoconstriction elicited by different types of vasoconstrictor agents. Such studies define the renal hemodynamic effects of CCBs.

\section{Materials and Methods}

Male wistar rats $(300 \pm 10 \mathrm{~g})$ having free access to food and tap water were anaesthetized with urethane $(0.15 \mathrm{~g} / 100 \mathrm{~g}$ i.p). After opening of the abdominal cavity by a ventricular incision, heparin was injected into the vena cava (500 U/kg) and renal artery was cannulated using a $20 \mathrm{G}$ needle with a polished tip via the superior mesenteric artery without disruption of flow. The ligatures around the cannula were tied and the kidney was removed and placed in a thermostated glass chamber contained perfusion medium with a constant temperature of $37^{\circ} \mathrm{C}$. The perfusion medium consisted of Krebs solution materials with the following composition $(\mathrm{mM}): \mathrm{NaCl} 118, \mathrm{KCl} 4.8, \mathrm{MgSO}_{4}, 7 \mathrm{H}_{2} \mathrm{O} 1.2, \mathrm{CaCl}_{2} 2.5$, $\mathrm{KH}_{2} \mathrm{PO}_{4} 1.2$ and Glucose 10 and equilibrated with a gass mixture of $95 \% \mathrm{O}_{2}$ and $5 \% \mathrm{Co}_{2}$.

Perfusion was initiated in situ with a constant flow at $85-95 \mathrm{mmHg}$. Perfusion medium was fed to the kidney by means of a peristaltic pump (LKB, Varioperpex II) through PTFE tubings (Pharmacia Biotech, 18-8207-01). 
The renal artery pressure was monitored through a pressure transducer (Beckman, 4-327) situated parallel to perfusion cannula and was recorded on a Beckman polygraph (R-612).

The drugs were injected by using a load-inject valve placed in the perfusion circuit, just before the kidney. The valve provides two flow paths. In the load position, the valve connects the pump directly to the kidney. Using a syringe, the sample drug is injected into a loop with a small defined volume. In the inject position, the sample in the loop is directly inserted into the flow path of the perfusate and dose not alter the baseline pressure.

In the method we used, following the establishment of Isolated kidney perfusion and 30 minutes equilibration first the renal vasculature was constricted by injection of bolus doses of $0.5,2,5,10,50,100,200 \mu \mathrm{M}$ phenylephrine ( $\alpha_{1}$-agonist) to the perfusion line via load-inject pump. Changes in perfusion pressure from baseline perfusion pressure due to phenylephrine (PE) injection were recorded on a physiograph trace. Then DHPs calcium channel blockers nifedipine, mebudipine or dibudipine $(1,5,10 \mu \mathrm{M})$ prepared in perfusion medium, was fed to the kidney by a peristaltic pump through PTEF tubings for 30 minutes. Finally alterations in perfusion pressure from baseline due to PE administration via loadinject pump in presence of CCBs were recorded. Of note, PE concentrations have been selected based on concentration response-curve and in higher concentration of $\mathrm{PE}$ $(>200 \mu \mathrm{M})$ the curve takes a plateu shape.

All DHPs were dissolved in dimethylsulfoxide (DMSO) and then diluted with krebs solution.

Maximum increase in perfusion pressure from baseline induced by PE injection $(200 \mu \mathrm{M})$ in the absence of CCBs was considered as $100 \%$ of response. PE-evoked increments in renal perfusion pressure in absence or presence of CCBs were expressed as percent increase in perfusion pressure. Data (percent increments in perfusion pressure) were analyzed by ANOVA using Nested design in MINITAB software and the relevant plots were drawn by Exell software.

$\mathrm{EC}_{50}$ was used to measure the potency of these DHPs by quantifying the inhibition of PEinduced increase in perfusion pressure as the primary response as done by other authors [14]. The observed increments in perfusion pressure in presence of increasing concentrations of DHPs were transformed into percent inhibition of perfusion pressure responses. These data also were analysed by ANOVA using Nested design in MINITAB software. The $\mathrm{EC}_{50}$ values of $\mathrm{CCBs}$ were calculated by fitting the data points into logistic model curve with $r$ values of not less than 0.94 using the Curve Expert 1.3 software and were analysed using Student's $t$-test. All data were expressed as means \pm S.E.M. A $P$ value $<0.05$ was considered to be significant.

The animal experiments were in accordacne with international guidelines and approved by the ethical committee of the Iranian University of Medical Sciences, Teheran, Iran.

\section{Results}

Our results indicated that new DHPs, mebudipine and dibudipine $(5,10 \mu \mathrm{M})$ reduced significantly increases in perfusion pressure induced by phenylephrine $(P<0.0001)$. A sample trace representing the inhibitory effect of mebudipine on perfusion pressure rise induced by PE injection was shown in Fig. 1. 


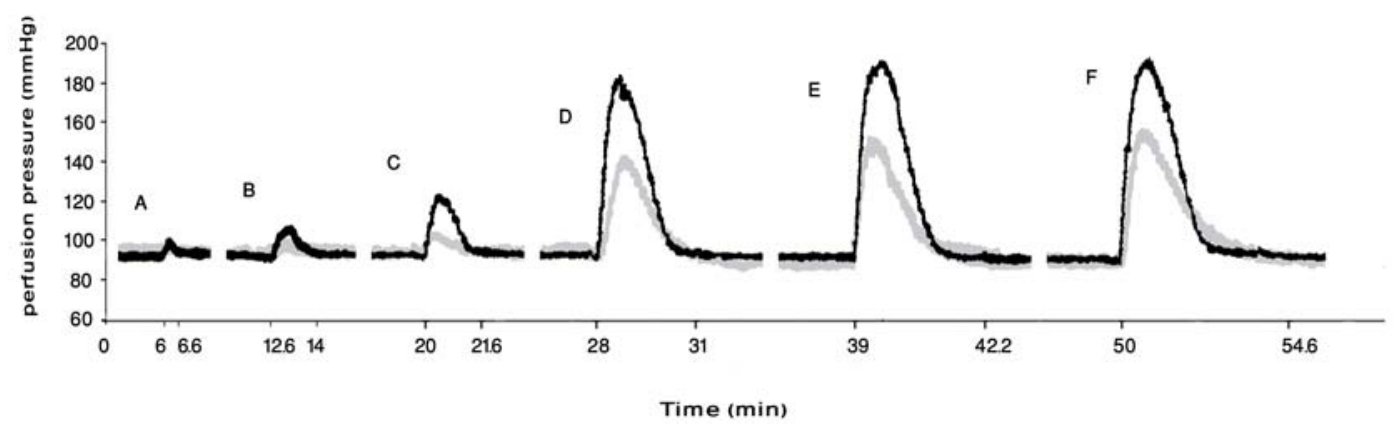

Fig. 1. A sample trace representing the inhibitory effect of mebudipine $(10 \mu \mathrm{M})$ on increases in perfusion pressure induced by increasing concentration of PE [2 $\mu \mathrm{M}(\mathrm{A}), 5 \mu \mathrm{M}(\mathrm{B}), 10 \mu \mathrm{M}(\mathrm{C}), 50 \mu \mathrm{M}(\mathrm{D}), 100 \mu \mathrm{M}(\mathrm{E}), 200 \mu \mathrm{M}(\mathrm{F})]$. PE-induced peak pressure rise in absence of meb (-),PE-induced peak pressure rise in presence of $10 \mu \mathrm{M}$ meb $(\square)$.

Mebudipine and dibudipine $(5,10 \mu \mathrm{M})$ elicited a concentration-dependent inhibition of PEinduced increase in renal perfusion pressure $(P<0.05$; Fig. 2; Fig. 3$)$.

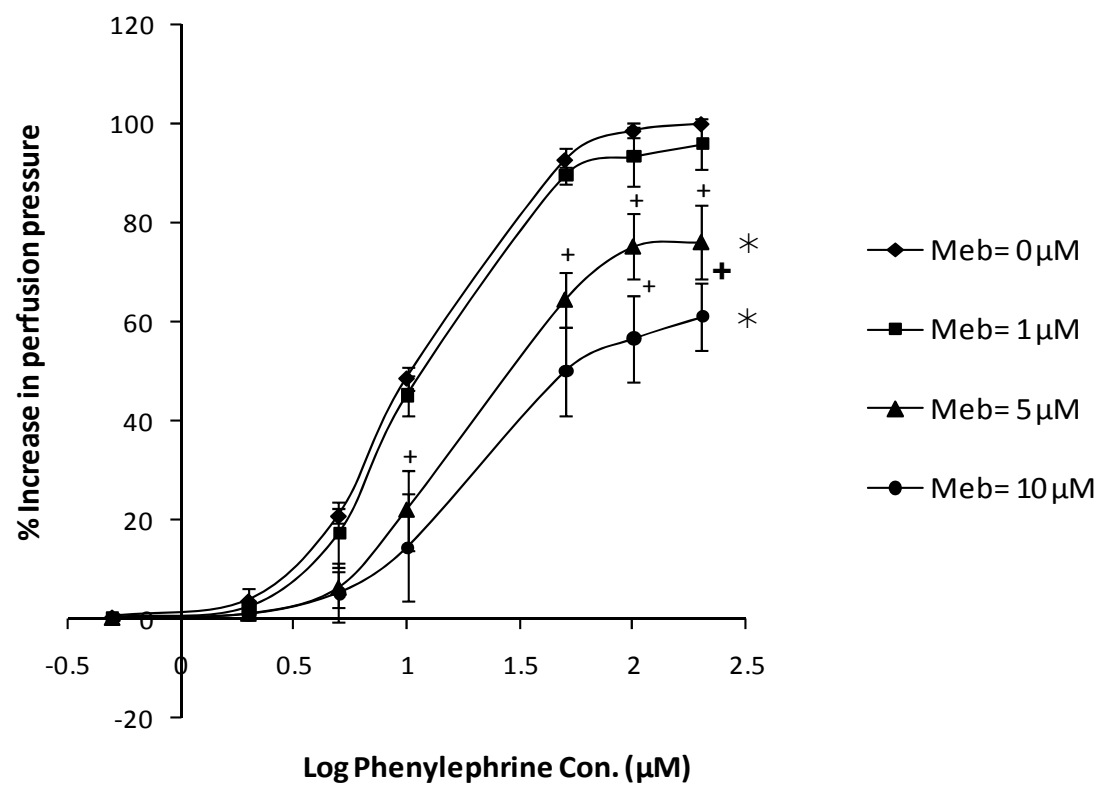

Fig. 2. The inhibitory effect of mebudipine on PE-induced increases in perfusion pressure. Value are means $\pm S . E . M$. from 5 kidneys. Alterations in perfusion pressure from basline induced by PE administration in presence or absence of CCB drugs were expressed as percent increase in perfusion pressure. \% Increases in perfusion pressure arising from $P E$ decreased significantly in presence of $5,10 \mu \mathrm{M}$ mebudipine $(* P<0.0001 \mathrm{vs}$. control group, across the curves). Mebudipine elicited concentration-dependent inhibition of response induced by phenylephrine. Mebudipine $(1 \mu \mathrm{M})$ did not reduce PE-induced response compared to control group. Mebudipine $(5,10 \mu \mathrm{M})$ show significant difference with each other in this respect $(+P<0.01 ;+P<0.05$, error bars). Mebudipine $(1,5 \mu \mathrm{M})$ also show significant difference with each other $(+P<0.01$, error bars). 


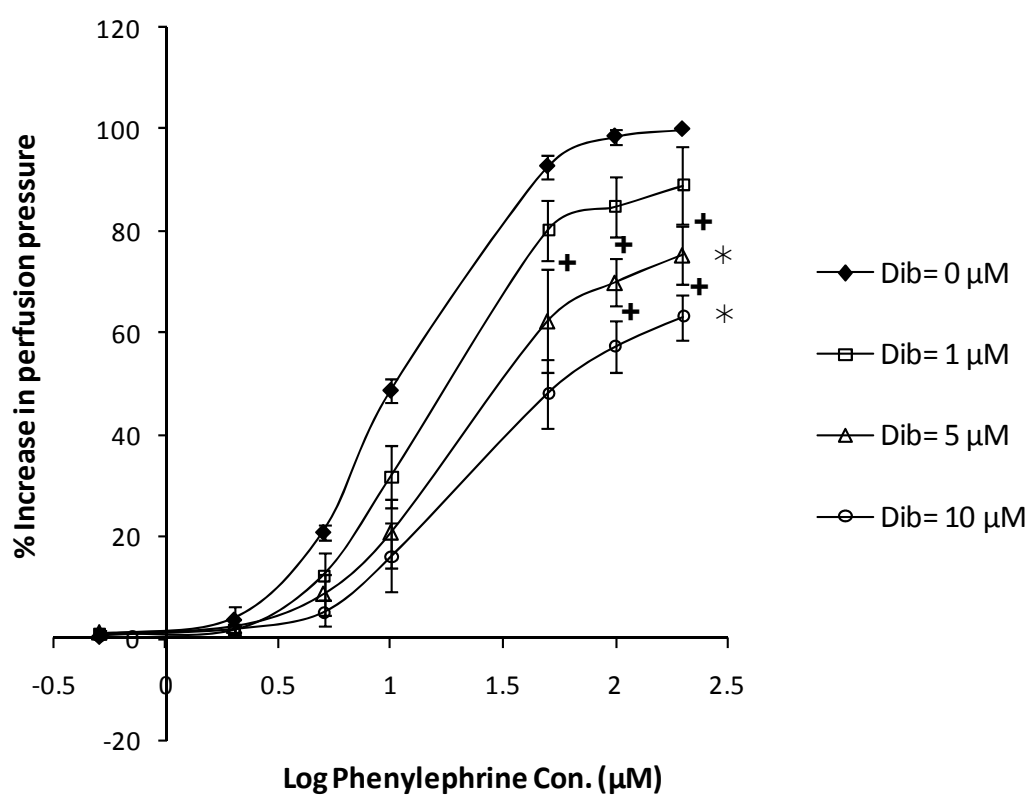

Fig. 3. The inhibitory effect of dibudipine on PE-induced increases in perfusion pressure. Value are means \pm S.E.M. from 5 kidneys. \% Increases in perfusion pressure induced by PE decreased significantly in presence of $(5 \mu \mathrm{M}, 10 \mu \mathrm{M})$ dibudipine ( $* P<0.0001$, vs. control group, across the curves). Dibudipine induced concentration-dependent inhibition of PE-evoked increases in perfusion pressure. Dibudipine $(1 \mu \mathrm{M})$ did not show significant difference compared to control group. Dibudipine $(1,5 \mu \mathrm{M})$ differed significantly from each other $(+P<0.05$, error bars). Dibudipine $(5,10 \mu \mathrm{M})$ also showed significant difference with each other $(+P<0.05$, error bars).

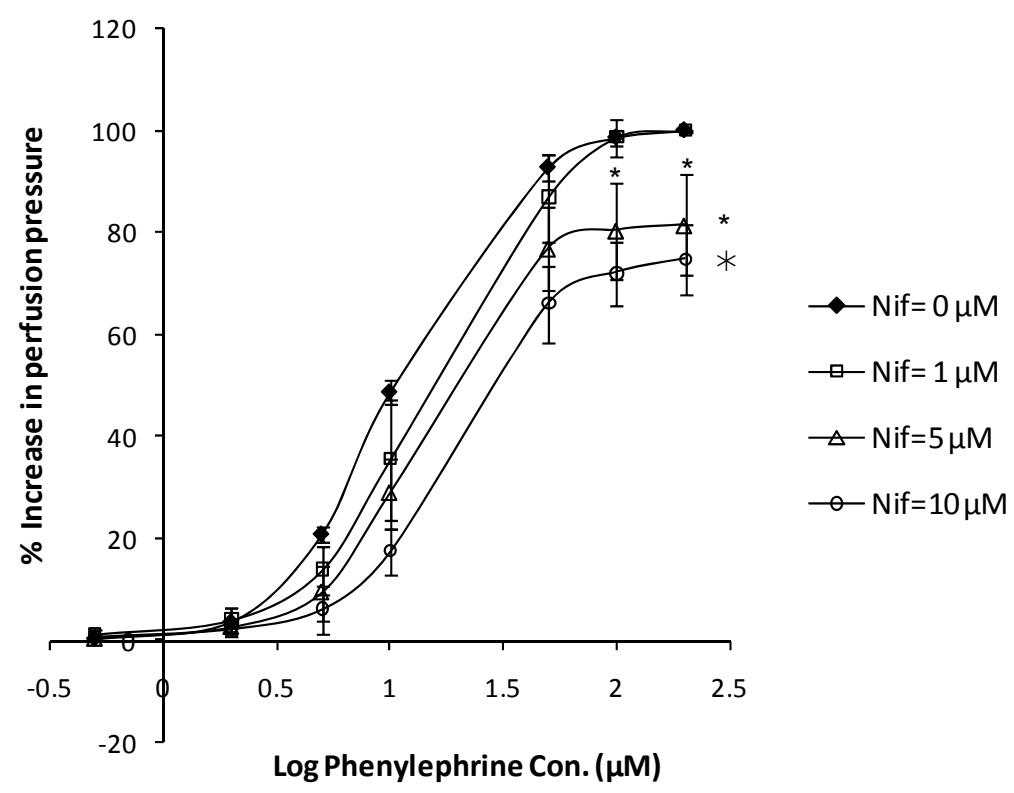

Fig. 4. The inhibitory effect of nifedipine on PE-induced increases in perfusion pressure. Value are means $\pm S$.E.M. from 5 kidneys. Alterations in perfusion pressure from baseline induced by PE administration in presence or absence of 
CCB drugs were expressed as percent increase in perfusion pressure. \% Increases in perfusion pressure arising from PE decreased significantly in presence of increasing concentrations of nifedipine $\left(5 \mu \mathrm{M}{ }^{*} P<0.001 ; 10 \mu \mathrm{M}\right.$ $* P<0.0001$, vs. control group). Nifedipine $5 \mu \mathrm{M}$ shows significant difference with nifedipine $1 \mu \mathrm{M}\left({ }^{\star} P<0.001\right.$, error bars). The signs across the curves show significant differences vs. control groups.

The data indicated that PE-induced increases in perfusion pressure decreased significantly in presence of 5, $10 \mu \mathrm{M}$ nifedipine (Fig. 4).

Our findings showed that the inhibitory effects of mebudipine and dibudipine in the same concentrations on PE-induced increases in perfusion pressure were not significantly different from each other (Fig. 5; Fig. 6). Increments in perfusion pressure arising from PE $(100,200 \mu \mathrm{M})$ in presence of $10 \mu \mathrm{M}$ mebudipine was significantly less than that in presence of $10 \mu \mathrm{M}$ nifedipine $(P<0.05$, Fig. 6$)$.

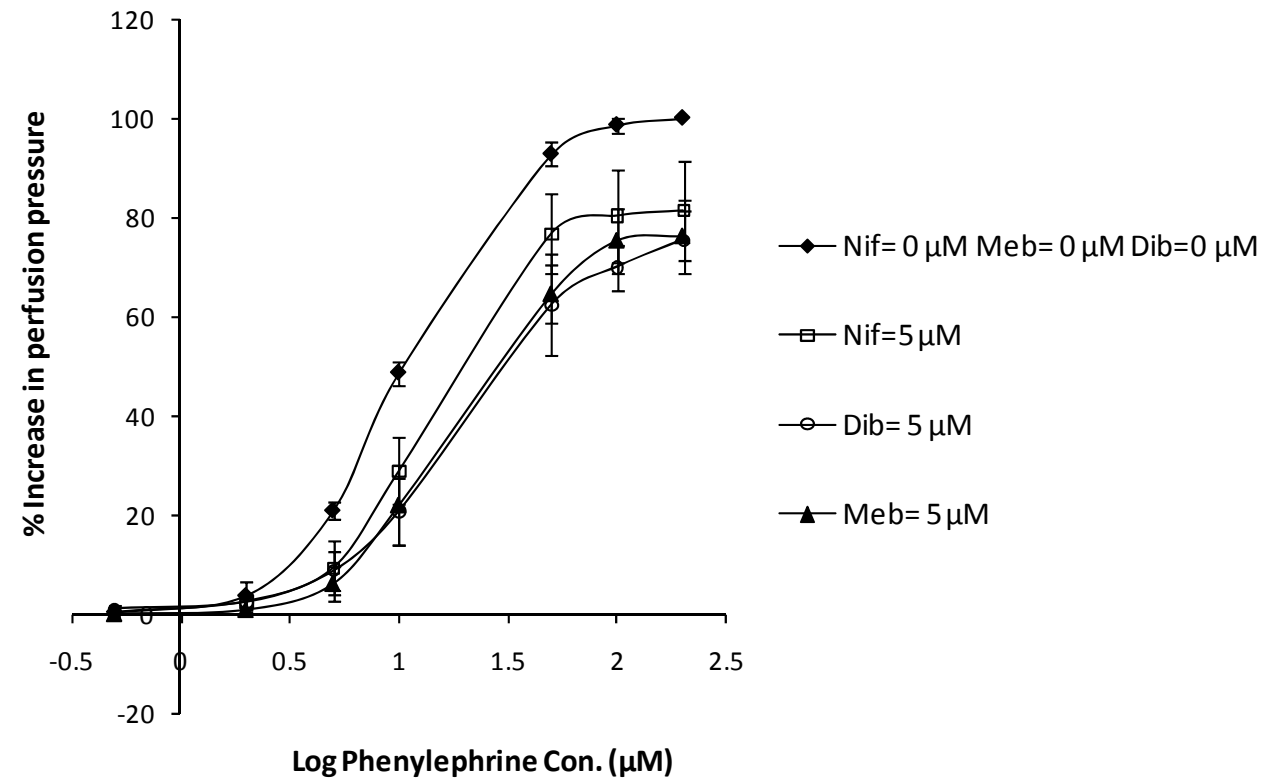

Fig. 5. The inhibitory effects of nifedipine, dibudipine and mebubipine $(5 \mu \mathrm{M})$ on PE-induced increases in perfusion pressure. Value are means \pm S.E.M. from 5 kidneys. Nifedipine $(5 \mu \mathrm{M})$ decreased significantly PE-induced responses compared to control group $(P<0.001)$. Dibudipine and mebudipine $(5 \mu \mathrm{M})$ also reduced significantly $P E$-induced responses compared to control group $(P<0.0001)$. The inhibitory effects of mebudipine and dibudipine $(5 \mu \mathrm{M})$ on PEinduced increases in perfusion pressure were approximately similar. Mebudipine $(5 \mu \mathrm{M})$ and dibudipine $(5 \mu \mathrm{M})$ did not show any significant differences with Nifedipine $(5 \mu \mathrm{M})$ in this respect. 


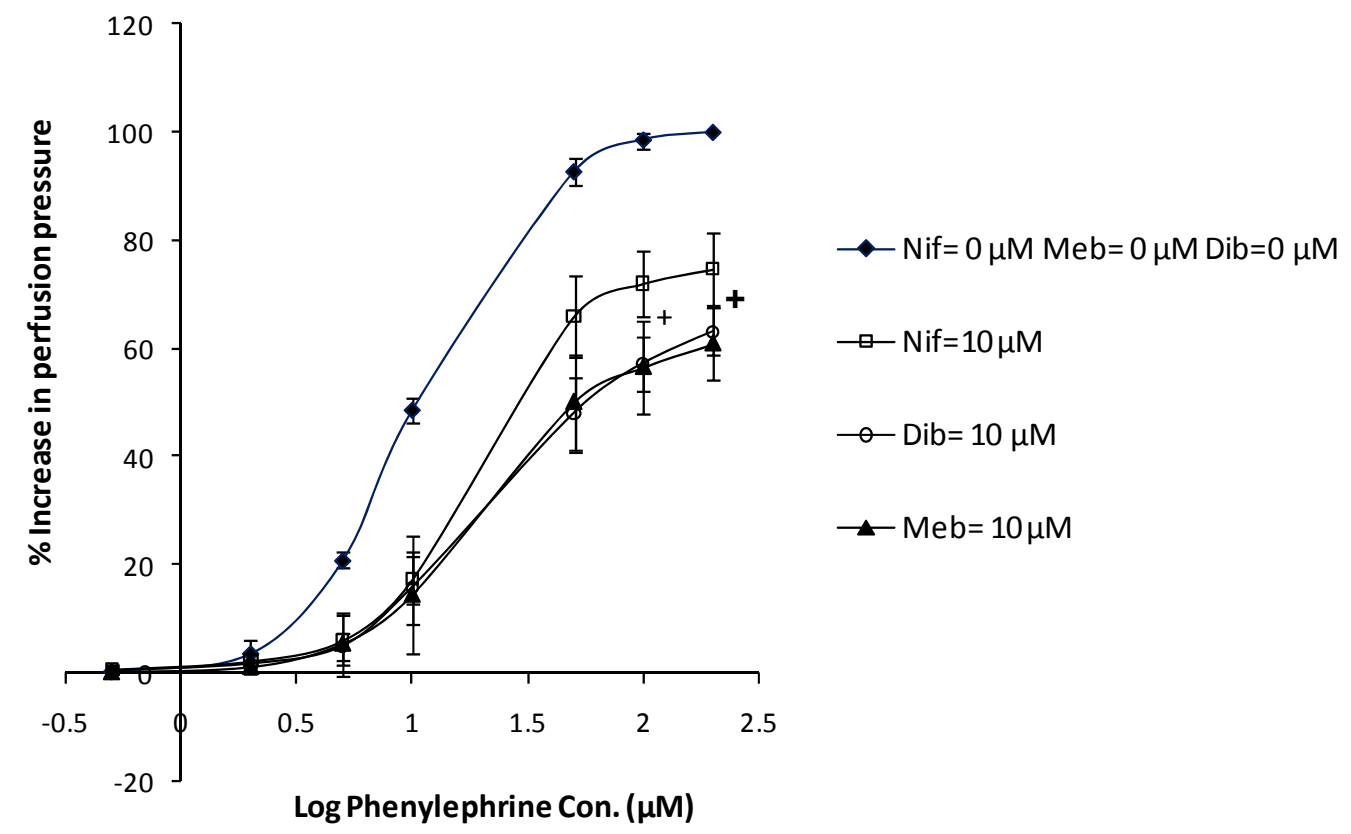

Fig. 6. The inhibitory effects of nifedipine, dibudipine and mebudipine (10 $\mu \mathrm{M})$ on PEinduced increases in perfusion pressure. Value are means \pm S.E.M. from 5 kidneys. Nifedipine $(10 \mu \mathrm{M})$ inhibited significantly PE-induced increases in perfusion pressure $(P<0.0001)$. Dibudipine and mebudipine $(10 \mu \mathrm{M})$ also reduced significantly PE-induced responses $(P<0.0001)$. The data analysis indicated that increments in perfusion pressure arising from PE $(100,200 \mu \mathrm{M})$ in presence of $10 \mu \mathrm{M}$ mebudipine was significantly less than that in presence of 10 $\mu \mathrm{M}$ nifedipine $(+P<0.01 ;+P<0.05)$. Dibudipine $(10 \mu \mathrm{M})$ did not show significant difference with nifedipine $(10 \mu \mathrm{M})$ in this respect.

Based on the concentration-response curve for DHP-induced inhibition (Fig. 7), the inhibitory effect of mebudipine $(10 \mu \mathrm{M})$ on perfusion pressure induced by $P E\left(E_{\max }\right.$ of $\left.P E\right)$ was greater as compared to $10 \mu \mathrm{M}$ nifedipine $(P<0.05)$. The effect of dibudipine $(10 \mu \mathrm{M})$ was not significantly different from nifedipine $(10 \mu \mathrm{M})$ in this respect. Calculated $\mathrm{EC}_{50}$ values of mebudipine, dibudipine and nifedipine (table1) did not show any significant differences with each other.

Tab. 1. $\quad E_{50}$ values of mebudipine, dibudipine and nifedipine for inhibition of PEinduced perfusion pressure in isolated rat kidney.

\begin{tabular}{ll}
\hline & EC $_{50}$ \\
\hline Mebudipine & $4.31 \pm 0.55$ \\
Dibudipine & $3.24 \pm 0.64$ \\
Nifedipine & $4.40 \pm 0.32$ \\
\hline Value are means \pm S.E.M. from 5 kidneys.
\end{tabular}




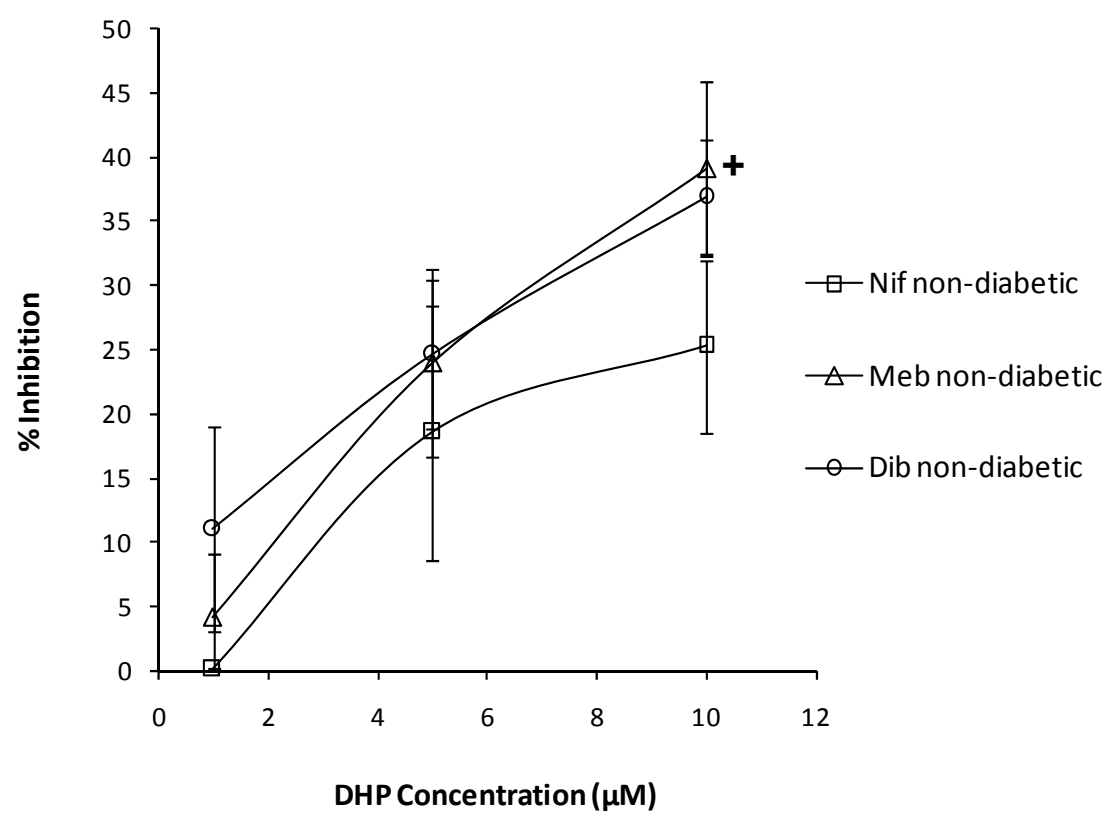

Fig. 7. The concentration-response curve for DHP-induced inhibition. Value are means \pm S.E.M. from 5 kidneys. Data analysis showed that inhibitory effect of mebudipine $(10 \mu \mathrm{M})$ on PE-induced increments in perfusion pressure $\left(E_{\max }\right.$ of $P E)$ was significantly greater than that of nifedipine $(+P<0.05)$. The effect of dibudipine $(10 \mu \mathrm{M})$ was not significantly different from nifedipine $(10 \mu \mathrm{M})$ in this respect.

\section{Discussion}

Previous findings showed that mebudipine and dibudipine had identical pharmacological effects to the prototype 1,4-DHP nifedipine, whilst possessing some advantages such as longer biological half life, longer duration of action, slower rate of absorption, fewer side effects and more vasoselectivity [9-11].

Mebudipine and dibudipine showed a vasorelaxant effect on human as well as animal artery preparations $[11,15]$. Mebudipine also showed a more potent vasorelaxant effect on isolated rat aorta compared to nifedipine [7].

The present study indicates that these new DHPs cause concentration-dependent inhibition of increase in perfusion pressure induced by $P E$ administration arising from constriction of renal microvessels. PE activate G-protein-coupled cell surface $\alpha_{1-}$ adrenoceptor subtypes and cause contraction by virtue of their ability to increase cytosolic calcium concentration [16]. Within the kidney $\alpha_{1 A}$-adrenoceptors have been consistently found to predominate over the $\alpha_{1 B}$ and $\alpha_{1 D}$, both in terms of density and functionality. Activation of $\alpha_{1 A}$-adrenoceptors cause constriction of renal vascular resistance bed. L-type $\mathrm{Ca}^{2+}$ channels appear to be coupled to $\alpha_{1 \mathrm{~A}}$-adrenoceptors and are opened when the receptor is activated [17]. DHPs reduced $\mathrm{Ca}^{2+}$ entry via L-type voltage gated $\mathrm{Ca}^{2+}$ channels. Recent reports suggested that DHPs may also inhibit other $\mathrm{Ca}^{2+}$-entry pathways [18]. 
Our findings show that nifedipine, mebudipine and dibudipine inhibit PE-induced increments in perfusion pressure. The inhibitory effects of mebudipine on PE ( $\left.E_{\max }\right)^{-}$ induced increments in perfusion pressure are greater than that of nifedipine. Mebudipine and dibudipine are two potent and selective L-type calcium channel blockers [15]. It has been proposed that mebudipine has a greater affinity to bind to inactivated channels, compared to nifedipine [19]. Given that mebudipine and dibudipine have more selectivity for the vessels upon which they act also they have longer half life and long lasting action comparing to nifedipine with a short half life and a short duration of vasodilation action and not that all vasoselectivity effects, these findings are not out of expectation.

It has been suggested that the most plausible explanation of vasoselective action of mebudipine is its probable great voltage-dependent action. It is well known that DHP derivative CCBs show greater potency toward tissues with higher (more positive) resting potential but this voltage-dependency varies among them [19].

Previous researches have shown that intraperitoneal and oral administration of mebudipine and dibudipine reduced systolic blood pressure in normotensive rats [11]. It was found that intraperitoneal administration of mebudipine and dibudipine also lowered systolic blood pressure significantly in hypertensive rats. Comparing $E D_{50}$ of the drugs showed more potent hypotensive effect for mebudipine comparing to nifedipine in hypertensive rats [20].

In a previous study it has been found that 55\% Ca2+ current in Helix neurons are carried by L-type Channels which were selectively blocked by DHPs [21]. Mebudipine and dibudipine also showed a higher potency in inhibiting the calcium evoked spikes in Helix aspersa as compared with nifedipine [12].

Mebudipine and dibudipine inhibit increases in renal perfusion pressure arising from PE by blocking L-type calcium channel. The inhibitory effect of mebudipine on increments in renal perfusion pressure induced by PE $(200 \mu \mathrm{M})$ is significantly greater than that of nifedipine. It implicate that mebudipine may therefore be suitable for further development in the view of their comparable pharmacological activity to nifedipine.

\section{Acknowledgements}

The authors thank Dr. Ebrahimi for his scientific assistance.

\section{Abbreviations}

CCB...calcium channel blockers(s)

DHP...dihydropiridine(s)

PE...phenylephrine

\section{Authors' Statements}

\section{Competing Interests}

The authors declare no conflict of interest. 


\section{Animal Rights}

The institutional and (inter)national guide for the care and use of laboratory animals was followed. See the material and methods part for details.

\section{References}

[1] López-Hernández FJ, López-Novoa JM.

The lord of the ring: Mandatory role of the kidney in drug therapy of hypertension.

Pharmacol Ther. 2006; 111: 53-80.

doi:10.1016/j.pharmthera.2005.08.002

[2] Reams GP.

Do Calcium channel blockers have renal protective effects?

Drugs Aging. 1994; 4: 263-287.

PMid:7827397

[3] Xu B, Xiao-hong L, Lin G, Queen L, Ferro A.

Amlodipine, but not verapamil or nifedipine, dilates rabbit femoral artery largely through a nitric oxideand kinin-dependent mechanism.

Br J Pharmacol. 2002; 136: 375-382.

doi:10.1038/sj.bjp.0704753

[4] Hayashi K, Wakino S, Sugano N, Ozawa Y, Homma K, Saruta T.

$\mathrm{Ca}^{2+}$ Channel Subtypes and Pharmacology in the Kidney.

Circ Res. 2007; 100: 342-353.

doi:10.1161/01.RES.0000256155.31133.49

[5] Hayashi K, Ozawa u, Fujiwara K, Wakino S, Kumagai H, Saruta T.

Role of Actions of Calcium Antagonists on Efferent Arterioles - with Special References to Glomerular Hypertension.

Am J Nephrol. 2003; 23: 229-244.

doi:10.1159/000072054

[6] Fleckenstien A.

Specific pharmacology of calcium in myocardium, cardiac pacemakers, and vascular smooth muscle. Annu Rev Pharmacol Toxical. 1977; 17: 149-166.

doi:10.1146/annurev.pa.17.040177.001053

[7] Mahmoudian M, Mirkhani H, Nehardani Z, Ghiaii S.

Synthesis and biological activity of two new calcium channel blocker, mebudipine and dibudipine.

J Pharm Pharmacol. 1997; 49: 1229-1233.

PMid:9466348

[8] Opie LH, Yusuf S, Kubler W.

Current status of safety and efficacy of calcium channel blockers in cardiovascular disease: a critical analysis based on 100 studies.

Prog Cardiovasc Dis. 2000; 43: 171-196.

doi:10.1053/pcad.2000.7010

[9] Bohlooli S, Mahmoudian M, Skellern GG, Grant MH, Tetty JNA.

Metabolism of the dihydropyridine calcium channel blockers mebudipine and dibudipine by isolated rat hepatocytes.

J Pharm Pharmacol. 2004; 56: 1469-1475.

doi:10.1211/0022357044760

[10] Mahmoudian M.

Mebudipine and Dibudipine: A Review.

Iranian J Pharm Ther. 2003; 2: 25-29. 
[11] Mirkhani H, Omrani GR, Ghiaee S, Mahmoudian M.

Effect of mebudipine and dibudipine, two new calcium channel blockers, on rat left atrium, rat blood pressure and human internal mammary artery.

J Pharm Pharmacol. 1999; 51: 617-622.

PMid:10411222

[12] Faizi M, Janahmadi $H$, Mahmoudian $M$.

The effect of mebudipine and dibudipine, two new $\mathrm{Ca}^{2+}$ channel blockers, in comparison with nifedipine on $\mathrm{Ca}^{2+}$ spikes of $\mathrm{F} 1$ neuronal soma membrane in Helix aspersa.

Acta Physiol Hung. 2003; 90: 243-254.

doi:10.1556/APhysiol.90.2003.3.7

[13] Maack T.

Physiological evaluation of the isolated perfused rat kidney.

Am J Physiol. 1980; 238: F71-F78.

PMid:6987899

[14] Rouzrokh A, Ebrahimi SA, Rahbar-roshandel N, Mahmoudian M.

Effect of mebudipine and dibudipine, two new calcium channel blockers on voltage-activated calcium currents of PC12 cells.

Acta Physiol Hung. 2007; 94: 199-207.

doi:10.1556/APhysiol.94.2007.3.5

[15] Mahmoudian M, Shafiei M, Mirkhani H, Omrani GR.

Effects of different vasodilators on human internal mammary artery in vitro.

Adv Exp Med Biol. 1999; 471: 419-426.

PMid:10659175

[16] Khan MH, Sattar M, Abdullah NA, Johns EJ.

Influence of combined hypertension and renal failure on functional $\alpha_{1}$-adrenoceptor subtypes in the rat kidney.

Br J Pharmacol. 2008; 153: 1232-1241.

doi:10.1038/bjp.2008.13

[17] Armenia A, Munavvar AS, Abdullah NA, Helmi A, Johns EJ.

The contribution of adrenoceptor subtype(s) in the renal vasculature of diabetic spontaneously hypertensive rats.

Br J Pharmacol. 2004; 142: 719-726.

doi:10.1038/sj.bjp.0705842

[18] Zhang J, Berra-Romani R, Sinnegger-Brauns MJ, Striessnig J, Blaustein MP, Matteson DR. Role of $\mathrm{Ca}_{\mathrm{v}} 1.2 \mathrm{~L}$-type $\mathrm{Ca}^{2+}$ channels in vascular tone: effects of nifedipine and $\mathrm{Mg}^{2+}$.

Am J Physiol Heart Circ Physiol. 2007; 292: H415-H425.

doi:10.1152/ajpheart.01214.2005

[19] Mirkhani H, Dirin M, Youssef-zayeh I.

Machanism of vasoselective action of mebudipine, a new calcium channel blocker.

Vascul Pharmacol. 2004; 42: 23-29

doi:10.1016/j.vph.2004.12.002

[20] Faizi M.

An investigation of electrophysiological and Pharmacological efects of two new drugs; mebudipine and dibudipine.

Iran Univ. Med. Sci. pulication; library registration no. 1267. 2003.

[21] Bai R, Janahmadi M, Green GGR, Sander DJ.

Effect of calcium channel blockers on transient outward currents F76 and D1 neuronal soma membrane of the subesophageal ganglion of Helix aspersa.

J Member Biol. 2000; 175: 179-185.

doi:10.1007/s002320001018 